\title{
User settings for advertising optimization on Facebook: Active customer participation or settings blindness?
}

Published in: Telematics and Informatics, 59 (2021), 101548

https://doi.org/10.1016/j.tele.2020.101548

\section{Rasia Haji}

Heinrich Heine University Düsseldorf, Germany, Dept. of Information Science rasia.haji@hhu.de

\section{Wolfgang G. Stock}

University of Graz, Austria, Department of Operations and Information Systems Heinrich Heine University Düsseldorf, Germany, Dept. of Information Science stock@phil.hhu.de 


\title{
User settings for advertising optimization on Facebook: Active customer participation or settings blindness?
}

\begin{abstract}
Facebook and many other social media companies act on information markets with various player groups, which are differentiated by the kind of payment, one group paying with money (normally, advertisers) and the other group paying with their personal data or their attention (i.e., Facebook's users being simultaneously the advertisers' potential customers). In order to minimize users' problems with (rather annoying) ads on digital services, some providers offer user settings for the optimization of advertising. We analyzed the information behavior of Facebook users concerning ad settings with the help of an online survey $(\mathrm{N}=1,021)$. Only about $40 \%$ of participating Facebook users know about personalization of settings of their advertising preferences. More than $20 \%$ of the users who work with Facebook's advertising optimization are satisfied since the changes, but 35\% are unsatisfied, and another $32 \%$ have a generally negative attitude towards online advertising. To describe customers' disregard or ignorance of settings we introduce the term "settings blindness.” Especially the users' gender and their educational background influence the information behavior concerning advertisement settings. The results have practical implications for Facebook users (namely, setting their own preferences for ads and thus seeing only personally customized ads), for Facebook and other social media companies (producing less annoying ads leading to a better customer loyalty and maybe more trust in the service), and for advertisers on social media (improving the correct addressing of the target groups).
\end{abstract}

\section{Keywords}

Online advertising; User settings; Information behavior; Facebook; Advertising optimization; Settings blindness

\section{Highlights}

- A newly introduced tool to social media advertising is Facebook's option to set ad preferences by the users.

- Using this tool optimally would lead to benefits for customers, suppliers of social media services, and advertisers on these services.

- A weakness of the current practice by Facebook is the high level of customer dissatisfaction as a result of Facebook's updating the ad preferences so quickly without informing the users about the changes.

- Many customers fail to see or ignore settings for ad preferences. Here, the problem of settings blindness arises. 


\section{Introduction}

In the light of internet technologies and social media, everyday life and technological progress have been linked and are now inevitable factors influencing the economy, society and their developments. Especially social networking services (SNSs) have become increasingly important, leading to changes in the daily lives of humans and causing an impact on many parts of the world's population in the $21^{\text {st }}$ century (Knautz and Baran, 2016). SNSs as many other social media companies act on markets with various player groups, which are differentiated by the kind of payment, one group paying with money and the other group paying with their data or their attention (Stock, 2020). This is similar to the phenomenon of network externalities implicating the existence of two-sided markets (Rochet and Tirole, 2003; Rochet and Tyrole, 2006). Players on SNS markets must "get both sides of the market on board" (Rochet and Tirole, 2003, p. 990), one market side being end users of the SNS service (and being simultaneously potential customers of the advertisers), the other side consisting of advertising companies. Providers of SNSs offer their services to customers without any financial charges and are financed by revenues from advertising. For the service providers the ads are essential for survival; however, for the users they are rather annoying (Linde and Stock, 2011, p. 328) and consumers from different cultures respond differently to social media ads (Sung et al., 2020). Such information behavior of Facebook users is known as "ad avoidance" (van den Broeck et al., 2018; Miltgen et al., 2019; Tefertiller, 2020; Youn and Kim, 2019) or “ad skipping behavior” (Belache et al., 2017). "Information behavior” includes all human behavior concerning production, search, reception, and even avoidance of information (Bates, 2010; Fisher et al., 2005; Scheibe et al., 2016; Zimmer et al., 2018); information behavior research is a part of information science (Stock and Stock, 2013).

Facebook is the most popular SNS at present (Baran and Ghaffari, 2017, p. 34). In 2019, Facebook generated revenues of 70,697 million US-\$ almost exclusively with the selling of ads (Facebook, Inc., 2020, p. 33). As it is the only income for Facebook, it is very important for this SNS provider to keep its users in line (Baran et al., 2015, p. 433).

In marketing and also in social media advertising, "new tools have led to new practices" (Ford, 2019, p. 383). Such a new tool is Facebook's option to set advertising preferences by the users. In order to minimize the audience's problems with ads, Facebook works with a new mean of interactive and personalized marketing and offers user settings for the optimization of advertising as a form of user participation in the selection of personalized ads and as a tool to influence the amount of privacy data used by Facebook for advertising. At this point our research starts: How do Facebook users deal with the optimization settings for advertising? Do age, gender, or educational background influence the information behavior of Facebook users concerning their interactions with the advertising settings? For advertisers and social media companies, it is important to know whether such inclusion of active information behavior is accepted by the potential customers. If the potential target audience is specified by age, gender, or education, it is desirable to have knowledge on the concrete information behavior of these target groups. Our study is the first empirical approach on users' information behavior concerning advertising preferences on an SNS having practical implications for all stakeholders, 
customers (seeing only personally customized ads), suppliers of SNSs (producing less annoying ads) as well as advertisers on SNSs (improving addressing the target groups). What are the strengths and weaknesses of the interactive device of settings ad preferences and do such activities lead to an optimized relationship between Facebook, its users, and its advertisers?

\section{Advertising on Facebook and Facebook's ad settings}

There are lots of studies on social media advertising. Research includes the relations between advertising content and consumer engagement (Lee et al., 2018), informativeness and advertising creativity as key drivers of favorable behavioral responses to ads (Lee and Hong, 2016), the role of social media ads in the purchase-decision process (Powers et al., 2012), and the interplay of social media ads and other online efforts of a company leading the users' brand engagement (Yang et al., 2016). Additionally, we could identify meta-studies on the empirical evidence of advertising in social media (Knoll, 2016) and on theoretical challenges as well as future directions of research on social media advertising (Okazaki and Tylor, 2013). However, there are only few studies concerning personalization in social media advertising. Winter et al. (2021) report on the effects of monitoring users' digital traces for personalization. Aydin (2018) was able to show that personalization has a direct positive effect on advertising value, and Shanahan et al. (2019) detected hints that personalization in advertising positively impacts consumer brand loyalty. The setting of ad preferences by users is a step towards personalization of social media advertising.

One reason why advertisers are interested in working with Facebook and relying on its advertising system is because Facebook helps them to find their defined audience. Facebook can target them more or less precisely due to the amount of information that it accesses about its users. Ads and commercial posts on Facebook may affect consumers' behavior to like, to comment, or to share the posts to other users (Kim et al., 2019). Facebook realizes personalized advertising (van den Broeck et al., 2020) and collects detailed person-related data in an amount, which is dependent on the users' willingness to provide information in their profiles and, additionally, on the users' digital traces, which comprise their posts (texts, images, or videos), their "friends," the looked posts, the frequency of looking these posts, and their reactions on posts (likes, shares, and comments) (Brettel et al., 2015). Using these data, Facebook creates a profile for every user. On the other market side there are Facebook's advertising customers. For an ad, they have to define their goals (e.g., increasing traffic of their web site), their objectives (awareness, consideration, and conversion including several subcategories), their budget, and-most important-their audience, which is defined by location, age, gender, languages, interests (e.g., liked Facebook pages), behavior (as, for instance, purchase behavior), and connections (between the concrete user and the advertiser on Facebook) (Curran et al., 2011). If a user profile and an ad profile match, the ad is displayed to the user. The more information from both market sides, i.e. from customers and from advertisers, is collected, the better and the more purposeful is the ad. If a social media company runs more than one service (as Facebook Inc. with the social networking service Facebook, the image sharing platform Instagram, and the 
messengers WhatsApp and Facebook Messenger), there would be a clear advantage when the company combines all available data sets on the users. This is why the divergence loss is not as high compared to classic mass media where "promotional advertising is also displayed to uninterested and therefore irrelevant users" (Ruhrberg et al., 2017, p. 224). The visibility and the click-through rate of the advertisements are increasing while the expenses are minimized. So, advertising is not only cheaper but also made quicker and can be always displayed regardless of time.

Indeed, Facebook advertising affects companies’ brand image and consumers’ purchasing intention (Dehghani and Turner, 2015); however Facebook’s CEO Zuckerberg (2018) addressed a problem regarding advertisements on Facebook, stating that many users feel overwhelmed and disturbed by the large number of adverts shown on their newsfeed. Of course, "Facebook users do not visit the social networking site to see advertising” (van den Broeck et al., 2018, p. 470). As a solution for those problems, Facebook offers setting options to its users to individualize the advertisements. These can be found among the ad preferences. They are supposed to help the users to adjust the adverts to their needs to ensure that they are more interesting and less irritating for them.

Figure 1. Facebook’s setting options for topics of ad preferences (Source: Facebook.com)

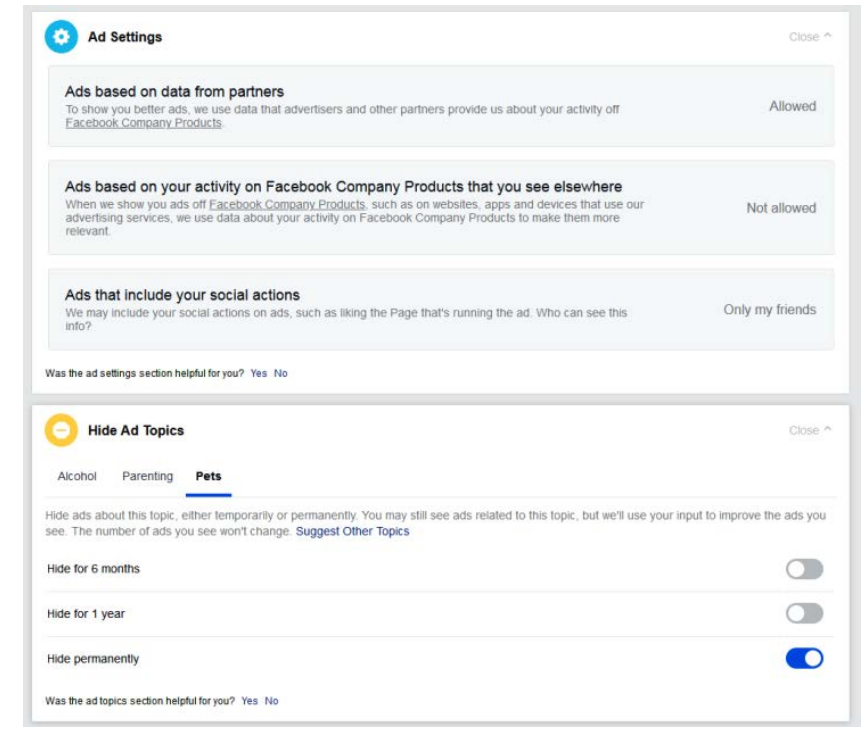

Figure 2. Facebook's disclosure of personal information and options to delete categories (Source: Facebook.com)

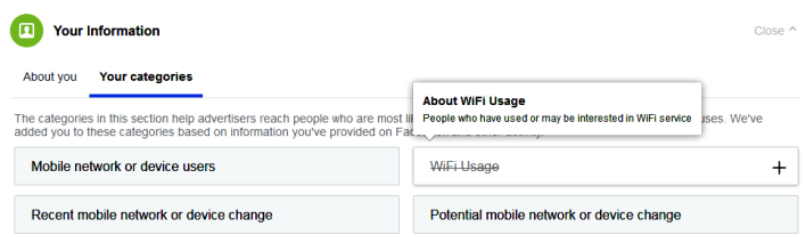


Figures 1 and 2 show how Facebook users are able to set preferences for ads. Facebook displays users' interests (e.g., in business and industry or in hobbies and activities) and allows to delete some of the interests. There are lists of businesses and advertisers who uploaded lists on Facebook giving the users the option to deselect certain companies. Users may allow or ban ads based on data from partners, ads based on users' activity on services owned by Facebook, ads including users' social actions, and the option to hide certain topics (Figure 1). Additionally, the users are able to see their own personal information (relationship status, employer, job title, and education) as well as content categories related to them (Figure 2). In the categories' setting, users may deselect topic categories. In the example of Figure 2, we deleted the category "WiFi Usage.”

Do Facebook users actually apply these options for advertisements? If so, are they more satisfied now? There are some studies on privacy settings on Facebook (e.g., Boyd and Hargittal, 2010; Liu et al., 2011); however, to our knowledge, there is no research that analyzes advertising settings. There are only two studies that broach the issue of ad preferences on Facebook. One of these studies analyzes the extent to which Facebook uses sensitive information like religion or sexuality for the purpose of finding advertisements and whether that is legal (Cabañas et al., 2018). The other study analyzes the transparency of Facebook ads and ascertains whether the explanations given for showing explicit advertising are complete, satisfying, and correct (Andreou et al., 2018). Both studies are indeed about the ad preferences, although they neglect to look at how users deal with the given setting options and if they even use or know about them.

Figure 3. Research model.

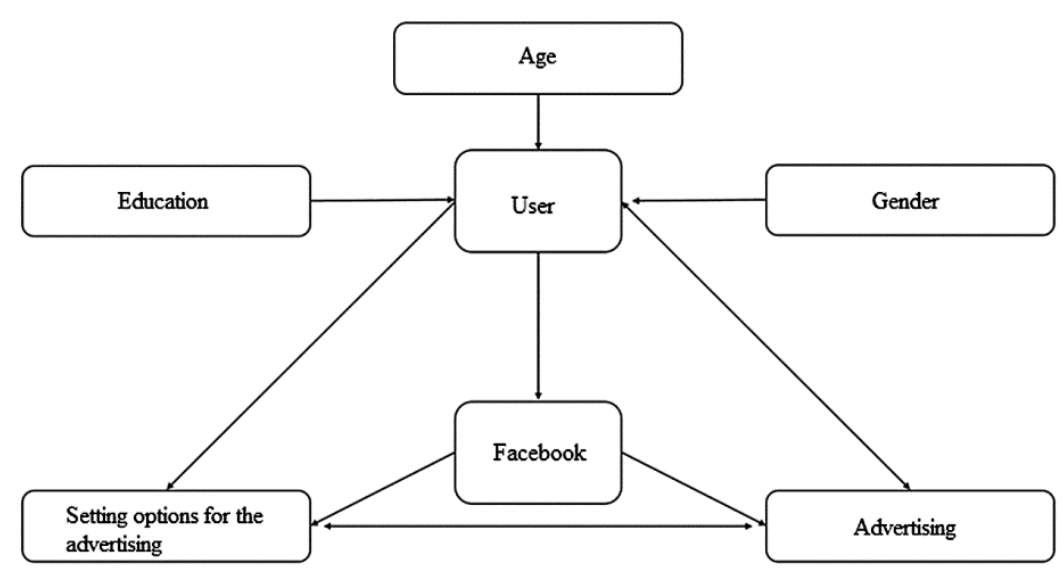

Our research sets the potential customer-the user-at the center (Figure 3). In this study, the users are described by their age, gender, and level of education. The user relates to Facebook through a Facebook account. Facebook targets its users for advertisement issues and gives the users the opportunity to actively personalize the advertisements by changing the advertisement settings via ad preferences. The article’s research questions are: 
- Research question 1: How do Facebook users deal with the optimization settings for advertising?

- Research question 2: Do age, gender, or educational background influence the information behavior of Facebook users concerning their advertising settings?

\section{Methods}

In information behavior research, we are able to use different data sources for data gathering including log files of the information systems, performing experiments with probands, systematic observations of the users' content, and, finally, asking the users (Zimmer et al., 2018, p. 442). As we want to know how users estimate a concrete tool of an information service, the best way to get data is by asking the users. For communication science, Katz et al. (1973, p. 511) states, "people are sufficiently self-aware to be able to report their interests and motives in particular cases.” Also in advertising research, surveys are frequently applied (Sarstedt et al., 2018); however, researchers have to prove adequate sampling. This study uses two different methods, namely the creation and implementation of an online questionnaire and a content analysis in order to analyze free text answers. For this study, an online questionnaire was created on the website umfrageonline.com. The questionnaire was anonymous, included fourteen questions and was published in German and distributed in German-speaking countries via Facebook groups. We applied non-probability sampling, more precisely convenience sampling (Vehovar et al., 2016), and hoped for representativity in German-speaking countries.

Most of the questions could be answered using a seven-point Likert scale. Thus-in contrast to methods applied in market research-, the respondents are not forced to give either positive or negative answers. Due to this kind of Likert scale, they can take a neutral stance if they feel unsure about a question by selecting number 4 , which is always the neutral response to the question asked (Likert, 1932, pp. $30 \mathrm{f}$.). 1 is always the most positive and 7 always the most negative answer option to the question.

Altogether, 1,244 people participated, although only those who have an active Facebook account and thus were able to finish the online questionnaire were considered relevant. Therefore, the number of participants was reduced to 1,021 people. The respondents needed to answer a question to reach the next one, whereby they were only able to switch between already-answered questions, so they were able to change an already-answered question after rethinking. It took about 3 to 5 minutes to answer all the questions. The questionnaire was broadly published via social networking services such as Facebook and Instagram. Before the questionnaire was published, it was pre-tested eight times and adjusted following suggestions of the pre-testers. It was possible to participate in the questionnaire from Dec 24, 2018 until Jan 18, 2019.

The data from the online survey were evaluated using the Statistical Package of the Social Sciences (SPSS). Our data are on an ordinal scale and show a normal distribution in only three cases. For this reason, it was decided to use the median, the interquartile range (IQR), and the 
Mann Whitney U-Test to test the significance for two independent samples (Mann and Whitney, 1947). In order to perform the U-Test, all respondents were divided into two groups according to their age, gender, and level of education. The confidence level for the U-Test was determined at $0.05(*), 0.01(* *), 0.001(* * *)$, and "not significant" (NS). In order to analyze the free text answers, content analysis was applied. Based on Krippendorff (2018), it can be used to analyze written communication of any kind. Therefore, the individual answers were analyzed and categorized inductively into four classes. In the next step, the free text answers were considered as units of evaluation and became classified into the four classes separately by one of the authors and another person. In the very few cases of disagreement (Krippendorff's Alpha always being $>0.8$ ) they discussed their results and agreed on the categorization in all cases.

\section{Demographics of the respondents}

The survey had a total of 1,021 participants. Their mean age is 27.64 years and the standard deviation is 10.98 years. 468 of the participants (45.84\%) are men and 529 (51.81\%) are women. Some people (2.35\%) did not want to indicate their gender. Following Statista (2018), in Germany, the age group with the most Facebook users is aged between 25 and 34 years. Of all German Facebook users, 52.8\% are men and 47.2\% are women. Concerning age, our sample seems to be representative, concerning gender, women are a little bit overrepresented in the sample.

286 people (28.01\%) have a general qualification for university entrance and 234 people (22.92\%) have a university graduation. Out of all respondents, 159 people (15.57\%) have a completed apprenticeship, and 111 (11.46\%) also have a somewhat limited qualification for university. 79 respondents (7.74\%) are still in school, and 108 (10.58\%) have a secondary school-leaving certificate. 28 participants (2.74\%) have no school-leaving qualifications at all, and the ten remaining people $(0.98 \%)$ have a doctor's degree. Most of the respondents live in Germany (97.36\%).

For the U-Test, the participants were always divided into two groups. The two different age groups comply with the generations defined by Fietkiewicz et al. (2016). For this study, Generation $\mathrm{Y}$ and $\mathrm{Z}$ are put together and represent one of the two categories named young, while Generation X, the Baby Boomers, and Silent Generation form the other group and are titled as old. The U-Test is also performed with gender, for which the categories male and female are used. The participants who provided no information about their gender are left out. The educational backgrounds are also divided into two groups. All of the participants who have a secondary school-leaving certificate, are still in school or have no school-leaving qualifications at all are in the group low. The others with a qualification for a university entrance, a completed apprenticeship or a university degree are in the group named high 


\begin{tabular}{|c|c|c|c|c|c|c|c|c|}
\hline \multicolumn{9}{|c|}{ 1.1. Frequency of advertising on Facebook $(\mathrm{N}=1,021)$} \\
\hline 1 & 2 & 3 & 4 & 5 & 6 & 7 & Median & IQR \\
\hline $20.47 \%$ & $22.82 \%$ & $19.39 \%$ & $30.07 \%$ & $3.92 \%$ & $2.25 \%$ & $1.08 \%$ & 3.00 & 2.00 \\
\hline \multicolumn{9}{|c|}{ 1: always; 4: sometimes; 7: never } \\
\hline \multicolumn{9}{|c|}{ 1.2. Opinion on advertising on Facebook $(\mathrm{N}=1,021)$} \\
\hline 1 & 2 & 3 & 4 & 5 & 6 & 7 & Median & IQR \\
\hline $3.04 \%$ & $4.02 \%$ & $7.05 \%$ & $35.65 \%$ & $24.19 \%$ & $15.08 \%$ & $10.97 \%$ & 5.00 & 2.00 \\
\hline \multicolumn{9}{|c|}{ 1: very appealing; 4 : neutral; 7 : very annoying } \\
\hline \multicolumn{9}{|c|}{ 1.3. Advertising as an obstacle $(\mathrm{N}=1,021)$} \\
\hline 1 & 2 & 3 & 4 & 5 & 6 & 7 & Median & IQR \\
\hline $7.54 \%$ & $5.48 \%$ & $18.81 \%$ & $44.07 \%$ & $13.61 \%$ & $6.27 \%$ & $4.21 \%$ & 4.00 & 1.00 \\
\hline \multicolumn{9}{|c|}{ 1: definitely; 4: sometimes; 7 : definitely not } \\
\hline \multicolumn{9}{|c|}{ 1.4. Optimizing advertising on Facebook $(\mathrm{N}=1,021)$} \\
\hline 1 & 2 & & & & & & & \\
\hline $40.06 \%$ & $59.94 \%$ & & & & & & & \\
\hline 1: yes; & 2: no & & & & & & & \\
\hline \multicolumn{9}{|c|}{ 1.5. Dealing with the optimization settings $(\mathrm{N}=409)$} \\
\hline 1 & 2 & 3 & 4 & 5 & 6 & 7 & Median & IQR \\
\hline $10.02 \%$ & $17.11 \%$ & $13.69 \%$ & $29.10 \%$ & $6.11 \%$ & $8.07 \%$ & $15.89 \%$ & 4.00 & 3.00 \\
\hline \multicolumn{9}{|c|}{$\begin{array}{l}\text { 1: dealt with them often and actively changed settings; } 4 \text { : dealt with them } \\
\text { somewhat; 7: neither dealt with them nor changed settings }\end{array}$} \\
\hline \multicolumn{9}{|c|}{ 1.6. Interest in (further) dealing with the advertisement settings ( $N=1,021)$} \\
\hline 1 & 2 & 3 & 4 & 5 & 6 & 7 & Median & IQR \\
\hline $8.42 \%$ & $11.26 \%$ & $15.38 \%$ & $32.71 \%$ & $8.33 \%$ & $7.84 \%$ & $16.06 \%$ & 4.00 & 2.00 \\
\hline \multicolumn{9}{|c|}{ 1: great interest; 4: maybe; 7: no interest } \\
\hline \multicolumn{9}{|c|}{ 1.7. User satisfaction since the changes $(n=344)$} \\
\hline 1 & 2 & 3 & 4 & 5 & 6 & 7 & Median & IQR \\
\hline $4.07 \%$ & $5.23 \%$ & $11.92 \%$ & $43.90 \%$ & $18.02 \%$ & $12.50 \%$ & $4.36 \%$ & 4.00 & 1.00 \\
\hline \multicolumn{9}{|c|}{ 1: very satisfied; 4 : neutral; 7 : very unsatisfied } \\
\hline \multicolumn{9}{|c|}{ 1.8. Feedback from respondents $(n=37)$} \\
\hline 1 & 2 & 3 & 4 & & & & & \\
\hline $21.62 \%$ & $10.81 \%$ & $35.14 \%$ & $32.43 \%$ & & & & & \\
\hline \multicolumn{9}{|c|}{$\begin{array}{l}\text { 1: satisfied since changes; } 2 \text { : neutral feedback; } 3 \text { : unsatisfied despite changes; } 4 \text { : } \\
\text { generally negative attitude towards advertising }\end{array}$} \\
\hline \multicolumn{9}{|c|}{ 1.9. Assessment of the promise of more control $(n=1,021)$} \\
\hline 1 & 2 & 3 & 4 & 5 & 6 & 7 & Median & IQR \\
\hline $10.58 \%$ & $9.11 \%$ & $19.88 \%$ & $41.04 \%$ & $10.09 \%$ & $6.95 \%$ & $2.35 \%$ & 4.00 & 1.00 \\
\hline
\end{tabular}

Table 1. Customers' dealing with advertising settings on Facebook. 


\section{Handling of the optimization settings for advertising (research question 1)}

The first research question is about how Facebook users, in their information behavior, deal with the optimization settings for Facebook advertising. Considering the frequency of noticing advertising on Facebook, Section 1.1. of Table 1 shows that most people chose the first four options as their answer, which overall means that more than $90 \%$ of the respondents notice advertising very often or at least sometimes. The neutral option 4 is the most commonlyselected answer. Regarding the general opinion on advertising on Facebook (1.2.), it can be said that most participants opted for 4 to 7 , which altogether shows that more than $85 \%$ of them find the advertising to be neutral to negative. Is advertising perceived as an obstacle? Most of the answers gather around the mid-point so there is no positive or negative trend as 4 is by far the most commonly-chosen answer (1.3.).

Now we arrive at the new interactive feature of SNSs, the settings of advertising preferences by the users. Regarding the optimizing advertising on Facebook, most of the respondents (about $60 \%$ ) do not know about the optimization settings (1.4.). Considering the dealing with the optimization settings, it can be observed that the given answers are distributed unevenly (1.5.). Many respondents chose option 4, but there are also about $41 \%$ dealing with the settings (votes 1 to 3 ) and 30\% who did use this option seldom or not at all. Also the interest in (further) dealing with the advertisement settings is not very keen (1.6.). The answers to questions 1.5. and 1.6 are rather similar.

Concerning their satisfaction since the changes respondents who really applied the ad settings chose the neutral answer (44\%), 21\% are more or less satisfied, and 35\% are unsatisfied. 37 participants used the free-text field to leave comments about their experience with adverts settings on Facebook. The content analysis of the comments' resulted in four main categories: satisfied since changes (22\%), neutral feedback (11\%), unsatisfied despite changes (35\%), and generally negative attitude towards advertising on Facebook (32\%) (1.8.). The unsatisfied participants said that they are disappointed by the settings because they still see irrelevant ads. They assume that their changes are only accepted for a short amount of time. Other participants used this field to show their general dislike towards advertising on Facebook. They wish they could turn off the advertising completely. In consideration of the assessment of the promise of more control, more than $80 \%$ of all respondents (including the "maybe" answers) have little or even no confidence in the promise of Facebook (1.9.).

\section{Impact of age, gender, and education on user behavior (research question 2)}

The second research question explores whether age, gender, and education of Facebook users are factors that influence their information behavior concerning advertising settings. Concerning the question about noticing the ads on Facebook, there are no significant differences concerning all three variables (2.1.). The research found a clear difference between the customers' educational level when it comes to the general opinion on advertising on Facebook. The participants with a higher education find the advertising to be more irritating comparing to the 
ones with a lower education (2.2.). In light of the test of the question about the advertising as an obstacle, there are no significant differences between our groups (2.3.). For all groups, advertising is an obstacle sometimes.

\subsection{U-Test: Frequency of advertising on Facebook}

\begin{tabular}{|l|l|c|c|c|c|}
\hline & & $\mathrm{n}$ & Median & IQR & Significance \\
\hline \multirow{2}{*}{$\begin{array}{l}\text { Age } \\
(\mathrm{n}=1,021)\end{array}$} & Young & 908 & 3.0 & 2.0 & 0.65 \\
\cline { 2 - 5 } & Old & 113 & 3.0 & 2.0 & NS \\
\hline \multirow{2}{*}{$\begin{array}{l}\text { Gender } \\
(\mathrm{n}=997)\end{array}$} & Male & 468 & 3.0 & 2.0 & 0.46 \\
\cline { 2 - 5 } & Female & 529 & 3.0 & 2.0 & NS \\
\hline \multirow{2}{*}{$\begin{array}{l}\text { Education } \\
(\mathrm{n}=1,021)\end{array}$} & High & 806 & 3.0 & 2.0 & 0.06 \\
\cline { 2 - 4 } & Low & 215 & 3.0 & 2.0 & NS \\
\hline
\end{tabular}

Scale: 1: always; 4: sometimes; 7: never

\subsection{U-Test: Opinion on advertising on Facebook}

\begin{tabular}{|l|l|c|c|c|c|}
\hline & & $\mathrm{n}$ & Median & IQR & Significance \\
\hline \multirow{2}{*}{$\begin{array}{l}\text { Age } \\
(\mathrm{n}=1,021)\end{array}$} & Young & 908 & 4.0 & 2.0 & 0.10 \\
\cline { 2 - 5 } & Old & 113 & 5.0 & 2.0 & NS \\
\hline \multirow{2}{*}{$\begin{array}{l}\text { Gender } \\
(\mathrm{n}=997)\end{array}$} & Male & 468 & 5.0 & 2.0 & 0.13 \\
\cline { 2 - 5 } & Female & 529 & 4.0 & 1.0 & NS \\
\hline \multirow{2}{*}{$\begin{array}{l}\text { Education } \\
(\mathrm{n}=1,021)\end{array}$} & High & 806 & 5.0 & 2.0 & 0.005 \\
\cline { 2 - 5 } & Low & 215 & 4.0 & 1.0 & $* *$ \\
\hline \multicolumn{7}{|l}{ Scale: 1: very appealing; 4: neutral; 7: very annoying } \\
\hline
\end{tabular}

\subsection{U-Test: Advertising as an obstacle}

\begin{tabular}{|c|c|c|c|c|c|}
\hline & & $\mathrm{n}$ & Median & IQR & Significance \\
\hline \multirow{2}{*}{$\begin{array}{l}\text { Age } \\
(n=1,021)\end{array}$} & Young & 908 & 4.0 & 1.0 & \multirow{2}{*}{$\begin{array}{c}0.95 \\
\text { NS }\end{array}$} \\
\hline & Old & 113 & 4.0 & 1.0 & \\
\hline \multirow{2}{*}{$\begin{array}{l}\text { Gender } \\
(n=997)\end{array}$} & Male & 468 & 4.0 & 1.0 & \multirow{2}{*}{$\begin{array}{l}0.13 \\
\text { NS }\end{array}$} \\
\hline & Female & 529 & 4.0 & 1.0 & \\
\hline \multirow{2}{*}{$\begin{array}{l}\text { Education } \\
(n=1,021)\end{array}$} & High & 806 & 4.0 & 1.0 & \multirow{2}{*}{$\begin{array}{c}0.38 \\
\text { NS }\end{array}$} \\
\hline & Low & 215 & 4.0 & 1.0 & \\
\hline \multicolumn{6}{|c|}{ Scale: 1: definitely; 4: sometimes; 7: definitely not } \\
\hline \multicolumn{6}{|c|}{ 2.4. U-Test: Dealing with the optimization settings } \\
\hline & & $\mathrm{n}$ & Median & IQR & Significance \\
\hline \multirow{2}{*}{$\begin{array}{l}\text { Age } \\
(n=409)\end{array}$} & Young & 351 & 4.0 & 2.0 & \multirow{2}{*}{$\begin{array}{c}0.10 \\
\text { NS } \\
\end{array}$} \\
\hline & Old & 58 & 3.0 & 3.0 & \\
\hline \multirow{2}{*}{$\begin{array}{l}\text { Gender } \\
(n=403)\end{array}$} & Male & 220 & 4.0 & 3.0 & \multirow{2}{*}{$\begin{array}{c}0.006 \\
* *\end{array}$} \\
\hline & Female & 183 & 4.0 & 3.0 & \\
\hline \multirow{2}{*}{$\begin{array}{l}\text { Education } \\
(n=409)\end{array}$} & \begin{tabular}{|l} 
High \\
\end{tabular} & 352 & 4.0 & 3.0 & \multirow{2}{*}{$\begin{array}{c}0.00002 \\
* * *\end{array}$} \\
\hline & Low & 57 & 5.0 & 3.0 & \\
\hline
\end{tabular}




\begin{tabular}{|c|c|c|c|c|c|}
\hline \multicolumn{6}{|c|}{ Scale: 1 : dealt with them often and actively changed settings; 4 : dealt with } \\
\hline \multicolumn{6}{|c|}{$\begin{array}{l}\text { 2.5. U-Test: Interest in (further) dealing with the advertisement } \\
\text { settings }\end{array}$} \\
\hline & & $\mathrm{n}$ & Median & IQR & Significance \\
\hline \multirow{2}{*}{$\begin{array}{l}\text { Age } \\
(n=1,021)\end{array}$} & Young & 908 & 4.0 & 2.0 & \multirow{2}{*}{$\begin{array}{c}0.40 \\
\text { NS }\end{array}$} \\
\hline & Old & 113 & 4.0 & 4.0 & \\
\hline \multirow{2}{*}{$\begin{array}{l}\text { Gender } \\
(\mathrm{n}=997)\end{array}$} & Male & 468 & 4.0 & 2.0 & \multirow{2}{*}{$\begin{array}{c}0.037 \\
*\end{array}$} \\
\hline & Female & 529 & 4.0 & 2.0 & \\
\hline \multirow{2}{*}{$\begin{array}{l}\text { Education } \\
(\mathrm{n}=1,021)\end{array}$} & High & 806 & 4.0 & 2.0 & \multirow{2}{*}{$\begin{array}{c}0.0007 \\
* * *\end{array}$} \\
\hline & Low & 215 & 4.0 & 3.0 & \\
\hline \multicolumn{6}{|c|}{ Scale: 1: great interest; 4: maybe; 7: no interest } \\
\hline \multicolumn{6}{|c|}{ 2.6. U-Test: User satisfaction since the changes } \\
\hline & & $\mathrm{n}$ & Median & IQR & Significance \\
\hline \multirow{2}{*}{$\begin{array}{l}\text { Age } \\
(\mathrm{n}=344)\end{array}$} & Young & 296 & 4.0 & 1.0 & \multirow{2}{*}{$\begin{array}{c}0.31 \\
\text { NS } \\
\end{array}$} \\
\hline & Old & 48 & 4.5 & 1.75 & \\
\hline \multirow{2}{*}{$\begin{array}{l}\text { Gender } \\
(n=340)\end{array}$} & Male & 188 & 4.0 & 1.0 & \multirow{2}{*}{$\begin{array}{c}0.40 \\
\text { NS }\end{array}$} \\
\hline & Female & 152 & 4.0 & 1.0 & \\
\hline \multirow{2}{*}{$\begin{array}{l}\text { Education } \\
(\mathrm{n}=344)\end{array}$} & High & 305 & 4.0 & 1.0 & \multirow{2}{*}{$\begin{array}{c}0.16 \\
\text { NS }\end{array}$} \\
\hline & Low & 39 & 4.0 & 2.0 & \\
\hline \multicolumn{6}{|c|}{ Scale: 1: very satisfied; 4: neutral; 7: very unsatisfied } \\
\hline \multicolumn{6}{|c|}{ 2.7. U-Test: Assessment of the promise of more control } \\
\hline & & $n$ & Median & IQR & Significance \\
\hline \multirow{2}{*}{$\begin{array}{l}\text { Age } \\
(n=1,021)\end{array}$} & Young & 908 & 4.0 & 1.0 & \multirow{2}{*}{$\begin{array}{c}0.09 \\
\text { NS }\end{array}$} \\
\hline & Old & 113 & 4.0 & 1.0 & \\
\hline \multirow{2}{*}{$\begin{array}{l}\text { Gender } \\
(\mathrm{n}=997)\end{array}$} & Male & 468 & 4.0 & 1.0 & \multirow{2}{*}{$\begin{array}{c}0.94 \\
\text { NS }\end{array}$} \\
\hline & Female & 529 & 4.0 & 1.0 & \\
\hline \multirow{2}{*}{$\begin{array}{l}\text { Education } \\
(\mathrm{n}=1,021)\end{array}$} & High & 806 & 4.0 & 1.0 & \multirow{2}{*}{$\begin{array}{c}0.009 \\
* *\end{array}$} \\
\hline & Low & 215 & 4.0 & 1.0 & \\
\hline & Scale: & tely; & aybe; 7: & tely r & \\
\hline
\end{tabular}

Table 2. Impact of age, gender, and education on advertising settings on Facebook.

The dealing with the optimization settings exhibits massive differences between the genders and the educational levels (2.4.). Both male and female respondents have a median of 4; however, they show differences in the concrete value distribution in their answers to this question. Answers of the men center towards the first four (positive) numbers of the Likert scale. Indeed, many men did make use of the optimization settings. Women mostly chose the neutral option 4 and decrease in number in the direction of option 1, which is the most positive value. A large part of the answers of women distribute at 6 and 7 , which means that there was little or no 
occupation with the setting options. Participants with a higher level of education have a median of 4 and those with a lower educational level a median of 5 . Those with a lower education have occupied themselves less with the setting options and made fewer changes than those with a higher education.

The interest in (further) dealing with the advertisement settings shows significant differences for gender and education (2.5). Though both genders have the same median, women are leaning towards option 4 and men more towards the most positive numbers 1 and 2. Respondents with lower education disagree more in their answers (IQR: 3 ) than those with higher education (IQR: 2) and form two sub-groups, namely people who have either no interest at all or a very big interest in engaging with the setting options.

The user satisfaction since the changes exhibits no statistically significant differences between our groups (2.6.). Concerning the promise of more control, there are very significant differences (again, in the value distribution, not in the median and IQR) between the respondents with high and with low educational level (2.7.). More than half of the respondents with the lower educational level chose option 4 . The distribution decreases on both sides of the scale. The group with the higher educational level mostly chose the first four options of the scale.

\section{Discussion}

There are not many respondents who do not notice the advertisements on Facebook. Most of them notice the advertisements anywhere from sometimes to very often. Their answers mostly spread among the first four points of the seven-point Likert scale (“always" to "sometimes”). The study of Roberts (2010, p. 30) also shows that most people are aware of advertisements on Facebook. She observes only a small number of users who do not notice advertisements.

Tran (2017) identified ad lovers, ad accommodators, and ad haters. Only a few respondents of our survey think the advertisements on Facebook are appealing. Most of the respondents find the advertisements neutral to negative leading to the known Facebook ad avoidance (Belanche et al., 2017; Miltgen et al., 2019; Tefertiller, 2020; Youn and Kim, 2019; van den Broeck et al., 2018). The neutral to negative tendency is confirmed in the post by Zuckerberg (2018). He reported that many Facebook users are burdened and annoyed by the advertisements. They feel like the Facebook posts of their friends and family are drowned out by the adverts. There are significant differences between the respondents' answers regarding their level of education. Those with a higher educational level find the advertisements more irritating than those with a lower educational level. There is also a relation to the previous question because before it was shown that participants with a higher educational level by comparison take more notice of the advertisements. Therefore, it makes sense that they categorize the advertisements on Facebook as more disruptive than the other group.

Is advertising perceived as an obstacle? The majority of our respondents thinks this holds true sometimes. Common activities on Facebook include viewing their friends' and family's posts. These posts can disappear in between all the adverts. For this instance, it is possible that the 
adverts stop or prevent Facebook users from their usual actions on the social networking service.

Do users know the interactive options of setting ad preferences? Most of the participants did not know about all of the interaction possibilities that Facebook offers to give its users more control over the advertising and their privacy data. Facebook has initiated many advertisements to spread information about the ad preferences. The campaign about the ad preferences was published in newspapers and journals, while there were also advertising video clips on television and outdoor advertisements with posters on public places like bus stops. Moreover, Facebook itself showed advertisements concerning the optimization settings. Nevertheless, more than half of the respondents do not know about these optimization possibilities. Our result is in line with the findings of Cabañas et al. (2018, p. 480). This could be connected to the fact that the users see the advertisements in general but do not take in their content. Benway and Lane (1998, p. 132) coined the term Banner Blindness for this phenomenon. The term means that advertisements are not taken in but ignored either by accident or on purpose and therefore are disregarded. Maybe there exists not only Banner Blindness, but also a Settings Blindness (or Settings Ignorance) leading users simply to ignore all kinds of settings (including ads settings) in their information behavior.

The next question shows an unexpected result. Here, it is asked whether the respondents have already made some changes in the advertisement settings provided that they know about these optimization options. The answers center towards option 4 as the focal point, so the respondents are mostly only partially dealing with the settings options. Since previous results show that the advertisements are seen by the majority and judged as neutral to negative, it could be assumed that most of the respondents already intensely deal with the setting options. Instead, one-sixth chose option 7 on the Likert scale, which means that they have never even confronted with these ad preferences. This could be the case because they wish for fewer advertisements and see no need in having more personalized content. The results show that the users do not wish for more individualized advertisements but rather fewer adverts in general. This could be a reason for the lack of interest in dealing with the setting options. Besides, there are significant differences in the information behavior of male and female respondents and between those groups with a lower and higher educational level. At this point, a connection to the first two questions can be made, where it was discovered that it is also the group of respondents with higher education that notices the advertisements more often and finds them to be more irritating. Therefore, it is only natural that they also engage more with the optimization settings.

Furthermore, it was investigated whether the respondents are interested in dealing with the setting options (more). The results show that there is a rather willingness to do so in the future. The answers concentrate on the first four options of the seven-point Likert scale. Essentially, there is a moderate to strong willingness for (further) occupation with the optimization settings for the advertisements. The median of 4 means "maybe.” It is interesting to note that still many of the respondents chose option 7, reflecting "no interest." Looking at these candidates, it can be seen that more than half of them have already made major changes in the settings for the adverts. Therefore, it can be assumed that they were unsatisfied after having made their changes 
and thus do not see any reason to busy themselves with these ad preferences again. For the others who did not do any changes but still chose option 7, it can be hypothesized that they do not care about the content of the adverts because they dislike them all. A strong interest in dealing with the optimization settings is seen with the people who did not know about them at all before the survey. Furthermore, there are significant differences according to the gender and level of education.

Are users satisfied since they made changes in their ad preferences? In the course of the content analysis, the answers of the respondents to the open question were put into four categories. The answers are divided into satisfied, neutral, unsatisfied, and "general dislike” categories. Many respondents used this free text field to show their general dislike for advertisements on Facebook, whereby they expressed their wish for fewer advertisements. However, it is not clear if these people are more satisfied or still unsatisfied after optimizing their advertisement settings. Furthermore, the neutral answers do not show if the changes were accepted by Facebook and if the adverts are more pleasing now. A lot of people say that they do not notice the ads and block them out, as already indicated by Banner Blindness. Moreover, some admit that they have only made minimal changes in the optimization settings and therefore are not able to give reliable statements about their experience. Those who are still unsatisfied after optimizing their ads settings to their preferences complain that the changes are only accepted for a short time. Here, the regularity factor plays a major role because Facebook always updates the interests and preferences by analyzing all of their users' online activities. This is why the ad preferences need to be controlled on a regular basis so that unwanted themes and subjects can be deleted. If this is not done regularly, undesired advertisements can pop up again after some time. The satisfied people express that the advertisements are more interesting and pleasing after their changes. It can be surmised that changes in the settings of the ad preferences are generally accepted and do actually work but need to be reviewed and controlled as Facebook always adds new information to each user account. There are also significant differences between male and female respondents with this question. The women have a higher median and a noticeably lower interquartile range than the male participants. This means that women tend more towards the negative categories in this question and are more likely to feel negative about the advertisements after dealing with the settings.

The final question shows that the majority of participants have no trust in the promise of more control over Facebook ads. Many participants do not believe the company and think of the promise as empty words. It is remarkable that many of those who did not deal with the optimization settings have no trust in the promise of Facebook Inc. This again could be a reason why some did not deal with those settings yet and perhaps will not do so in the future because why would users invest their time and busy themselves with these settings when they do not even believe in them? Accordingly, this is an important factor of users' information behavior regarding the willingness of the users to interact with the ad preferences. 


\section{Conclusion}

In general, this study has shown that most of the respondents have only occupied themselves with the interactive optimization possibilities of the advertising on Facebook to a small extent. Nevertheless, there is a moderate to strong willingness to do so (more) in the future. Most of the participants who already adjusted the advertising settings feel indifferent or negative about the results. One reason for this is that they wish to see less advertising in general and that they need to regularly go back and control their ad preferences because Facebook always updates them. Moreover, many do not fully trust the promise of Facebook. They take the promise of more control over advertising as empty words even though a lot of them did not even deal with the optimization settings yet.

Furthermore, this study explores whether there are significant differences in the information behavior of the participants according to their age, gender, or educational level. It was proven that the age is not as important as the gender and especially education when it comes to the users' behavior. In general, men dislike ads more than women (as seen in Table 2.2). And higher educated people are more annoyed by ads than lower educated participants (Table 2.2); however, the higher educated people are in turn more dealing with the advertising settings (Table 2.4 and 2.5).

This study encountered some limitations. The respondents answered the questions of the survey without supervision, so there is no way of knowing whether they were influenced by other people or problems with the internet. Furthermore, there are a little bit more women than men who participated and most of them had a rather high level of education. Besides, the participants were mostly young, meaning most of them were part of Generations Y and Z. Apart from that, almost all the respondents live in Germany, which could lead to a regional or cultural bias. Overall, this study cannot be an adequate representation of all Facebook users.

Surely other research is needed, because this is only an exploratory study. For further research, it could be interesting to publish the questionnaire in more languages not only to reach more people but to see if there are any differences between the participants according to their place of residence and their culture. In addition, the age categories should be examined to see whether there are also differences within the groups defined in this study. Moreover, there should be future work dealing with the people who know about the optimization options but are not willing to try them. We found differences in the users' information behavior mainly by gender and by education, but our empirical approach does not tell why these differences are present. We only analyzed ad settings, but not the content of the ads. Are there content-related differences (e.g., users looking mainly for leisure purposes versus users talking about private content with relatives)? What is needed in the end is a theory which allows of explanations of the observed information behavior.

In a comparative analysis, users of other services with ads settings (e.g., Google) should be surveyed and the data compared with those from Facebook. We only analyzed one group of stakeholders, namely users. Similarly, one should also study the reactions of the advertisers and the staff of the online services concerning settings of the user preferences for ads. In a more 
detailed view of the users, it should be helpful to analyze the applied devices (desktop computer or mobile phone), the use of ad blockers, the users' level of experience with ads (i.e., the amount of clicks on ads), the overall time spent on Facebook (also in comparison with other services) and the time passed with ads, etc.

Our study highlights an area of further research because many of the participants do not trust the promise of Facebook. A study carving out why people could feel like this and if this has an impact on how people deal with the optimization options is desirable. Future work should also consider Settings Blindness and it’s overcoming as research topics of interactive marketing.

\section{Implications for practice}

The strengths of ad preferences settings as a personalized advertising option in social networking services-in theory-are:

- for SNS users and potential customers of the advertising companies: setting their own preferences for ads and thus seeing only personally customized ads,

- for suppliers of SNSs: producing less annoying ads leading to a better customer loyalty and maybe more trust in the SNS, and

- for advertisers on SNSs: improving the correct addressing of the target groups.

Our results may be useful for marketers in order to craft better methods of providing ads to the customers and for internet service companies to develop more finely-tuned user functions of presenting ads. Generally speaking, it seems to be a good idea to let users participate actively in the selection of ads via ad settings. As it is known that most users do not like ads, their assessment of ads may change if they in their information behavior can co-determine the presentation of ads.

Main results of the present study concerning gender and education are that men dislike ads more than women and that higher educated people are more dealing with the advertising settings. With these results in mind both, SNS companies as well as advertisers are able to apply customized marketing strategies for well-educated men, well-educated women, less-educated men, and less-educated women in order to create awareness for ad settings and to overcome gender- and education-specific settings blindness.

The weaknesses of the current practice by Facebook are (1) a high level of dissatisfaction despite changes are made too often and (2) many users do not know about this offer. For Facebook it is important to inform even more of its users about these possibilities and try to implement further optimizations with the ad preferences, so the users are more satisfied. For van den Broeck (2019, p. 144) it is important for the advertising industry "to put more effort in educating users on their privacy and advertising settings." Weaknesses could be achieved, for example, by not updating the ad preferences so quickly or informing users with a message that the ad preferences have been updated to let them know. From the point of view of advertising companies, preference settings have the opportunity that potential customers make use of these 
optimization settings because this will enable them to reach their desired target group even more precisely and only reach people who are interested in their service or product. Therefore, the divergence loss will be even lower for companies. The threat for social media services and likewise for advertisers on those services is the high number of users who are basically annoyed at ads on SNSs and the amount of users suffering from Settings Blindness. 


\section{References}

Andreou, A., Venkatadri, G., Goga, O., Gummadi, K.P., Loiseau, P., Mislove, A., 2018. Investigating ad transparency mechanisms in social media: A case study of Facebook's explanations, in NDSS 2018, Network and Distributed Systems Security Symposium 2018, 18-21 February 2018, San Diego, CA, USA, pp. 1-15.

Aydin, G., 2018. Role of personalization in shaping attitudes towards social media ads. International Journal of E-Business Research 14 (3), 54-76.

Baran, K.S., Fietkiewicz, K.J., Stock, W.G., 2015. Monopolies on social network services (SNS) markets and competition law, in F. Pehar, C. Schlögl and C. Wolff, eds. Re:inventing Information Science in the Networked Society. Hülsbusch, Glückstadt, Germany, pp. 424-436.

Baran, K.S., Ghaffari, H., 2017. The manifold research fields of Facebook: A bibliometric analysis. Journal of Information Science Theory and Practice 5 (2), 33-47.

Bates, M.J., 2010. Information behavior, in M.J. Bates and M.N. Maack, eds., Encyclopedia of Library and Information Sciences ( $3^{\text {rd }}$ ed.). New York, NY: CRC, pp. 2381-2391.

Belanche, D., Flavián, C., Pérez-Ruede, A., 2017. User adaption to interactive advertising formats: The effect of previous exposure, habit and time urgency on ad skipping behavior. Telematics and Informatics 34 (7), 961-972.

Benway, J.P., Lane, D.M., 1998. Banner blindness: Web searchers often miss 'obvious’ links. Internetworking: ITG Newsletter 1 (3), 123-135.

Boyd, D., Hargittal, E., 2010. Facebook privacy settings: Who cares? First Monday 15 (8).

Brettel, M., Reich, J.C. Gavilanes, J.M., Flatten, T.C., 2015. What drives advertising success on Facebook? An advertising-effectiveness model measuring the effects on sales of 'likes' and other social-network stimuli. Journal of Advertising Research 55 (2), 162-175.

Cabañas, J.G., Cuevas, A., Cuevas, R., 2018. Unveiling and quantifying Facebook exploitation of sensitive personal data for advertising purposes, in: Proceedings of the $27^{\text {th }}$ USENIX Security Symposium, pp. 479-495.

Curran, K., Graham, S., Temple, C., 2011. Advertising on Facebook. International Journal of EBusiness Development 1 (1), 26-33.

Dehghani, M., Turner, M. 2015. A research on effectiveness of Facebook advertising on enhancing purchase intention of consumers. Computers in Human Behavior 49, $597-$ 600 .

Facebook Inc., 2020. Annual Report Pursuant to Section 13 or 15(d) of the Securities Exchange Act of 1934. United States Securities and Exchange Commission, Washington, DC.

Fietkiewicz, K.J., Lins, E., Baran, K.S., Stock, W.G., 2016. Inter-generational comparison of social media use: Investigating the online behavior of different generational cohorts, in 
$49^{\text {th }}$ Hawaii International Conference on System Sciences. IEEE, Washington, DC, pp. 3829-3838.

Fisher, K.E., Erdelez, S., McKechnie, L., 2005, Preface, in K.E. Fisher, S. Erdelez, and L. McKechnie, eds., Theories of Information Behavior. Medford, NJ: Information Today, pp. xix-xxii.

Ford, J.B., 2019. What do we know about social-media marketing? Journal of Advertising Research 59 (4), 383-384.

Katz, E., Blumler, J.G., Gurevitch, M., 1973. Uses and gratifications research. Public Opinion Quarterly 37 (4), 509-523.

Kim, T., Kim, H., Kim, Y., 2019. How do brands’ Facebook posts induce consumers' e-wordof-mouth behavior? Informational versus emotional message strategy: A computational approach. Journal of Advertising Research 59 (4), 402-413.

Knautz, K., Baran, K.S., eds., 2016. Facets of Facebook. De Gruyter, Berlin, Germany, Boston, MA.

Knoll, J., 2016. Advertising in social media: A review of empirical evidence. International Journal of Advertising 35 (2), 266-300.

Krippendorff, K., 2018. Content Analysis. An Introduction to Its Methodology, $4^{\text {th }}$ ed. Sage, Thousand Oaks, CA.

Lee, D., Hosanagar, K., Nair, H.S., 2018. Advertising content and consumer engagement on social media: Evidence from Facebook. Management Science 64 (11), 5106-5131.

Lee, J., Hong, I.B., 2016. Predicting positive user responses to social media advertising: The roles of emotional appeal, informativeness, and creativity. International Journal of Information Management 36 (3), 360-373.

Likert, R., 1932. A technique for the measurement of attitudes. Archives of Psychology 22, 555.

Linde, F., Stock, W.G., 2011. Information Markets. A Strategic Guideline for the I-Commerce. De Gruyter, Berlin, Germany, New York, NY.

Liu, Y., Gummadi, K.P., Krishnamurthy, B., Mislove, A., 2011. Analyzing Facebook privacy settings: User expectations vs. reality, in: IMC'11. Proceedings of the 2011 ACM SIGCOMM Conference on Internet Measurement. ACM, New York, NY, pp. 61-70.

Mann, H.B., Whitney, D.R., 1947. On a test of whether one of two random variables is stochastically larger than the other. Annals of Mathematical Statistics 18 (1), 50-60.

Miltgen, C.L., Cases, A.S., Russell, C.A., 2019. Consumers’ responses to Facebook advertising across PCs and mobile phones. A model for assessing the drivers of approach and avoidance of Facebook ads. Journal of Advertising Research 59 (4), 414-432.

Okazaki, S., Taylor, C.R., 2013. Social media and international advertising: Theoretical 
challenges and future directions. International Marketing Review 30 (1), 56-71.

Powers, T., Advincula, D., Austin, M.S., Graiko, S., Snyder, J., 2012. Digital and social media in the purchase-decision process: A special report from the Advertising Research Foundation. Journal of Advertising Research 52 (4), 479-489.

Roberts, K.K., 2010. Privacy and perceptions: How Facebook advertising affects its users. The Elon Journal of Undergraduate Research in Communications 1 (1), 24-34.

Rochet, J.-C., Tirole, J., 2003. Platform competition in two-sided markets. Journal of the European Economic Association 1 (1), 990-1029.

Rochet, J.-C., Tirole, J., 2006. Two-sided markets: A progress report. The RAND Journal of Economics 37 (3), 645-667.

Ruhrberg, S.D., Kirstein, G., Baran, K.S., 2017. User acceptance of personalized and contextspecific online advertising. Open Journal of Social Sciences 5 (3), 223-232.

Sarstedt, M., Bengart, P., Shaltonid; A.M., Lehmann, S., 2018. The use of sampling methods in advertising research: A gap between theory and practice. International Journal of Advertising 37 (4), 650-663.

Scheibe, K., Fietkiewicz, K.J., Stock, W.G., 2016, Information behavior on social live streaming services. Journal of Information Science Theory and Practice, 4 (2), 6-20.

Shanahan, T., Tran, T.P., Taylor, E.C., 2019. Getting to know you: Social media personalization as means of enhancing brand loyalty and perceived quality. Journal of Retailing and Consumer Services 47, 57-65.

Statista. 2018. Anzahl der Facebook-Nutzer nach Altersgruppen und Geschlecht in Deutschland im Januar 2018. Online: https://de.statista.com/statistik/daten/studie/512316/umfrage/anzahl-der-facebooknutzer-in-deutschland-nach-alter-und-geschlecht/.

Stock, W.G., 2020. N-ary information markets. Money, attention, and personal data as means of payment. Journal of Information Science Theory and Practice 8 (3), 6-14.

Stock, W.G., Stock, M., 2013. Handbook of Information Science. De Gruyter Saur, Berlin, Germany, Boston, MA.

Sung, Y.H., Kim, D.H., Choi, D., Lee S.Y., 2020. Facebook ads not working in the same way: The effect of cultural orientation and message construals on consumer response to social media ads. Telematics and Informatics 52, 101427.

Tefertiller, A., 2020. Cable cord-cutting and streaming adoption: Advertising avoidance and technology acceptance in television innovation. Telematics and Informatics 51, 101416.

Tran, T.P., 2017. Personalized ads on Facebook: An effective marketing tool for online markets. Journal of Retailing and Consumer Services 39, 230-242.

van den Broeck, E., 2019. When Ads Walk a Tightrope. Balancing Effectiveness and Privacy 
Issues of Personalized Advertising on Social Networking Sites. PhD Thesis, University of Antwerp, Dept. of Communication Studies.

van den Broeck, E., Poels, K., Walrave, M., 2018. An experimental study of the effect of ad placement, product involvement and motives on Facebook ad avoidance. Telematics and Informatics 35 (2), 470-479.

van den Broeck, E., Poels, K., Walrave, M., 2020. How do users evaluate personalized Facebook advertising? An analysis of consumer- and advertiser controlled factors. Qualitative Market Research 23 (2), 309-327.

Vehovar, V., Toepoel, V., Steinmetz, S., 2016. Non-probability sampling, in C. Wolf, D. Joye, T.W Smith, Y.-C. Fu, eds., The SAGE Handbook of Survey Methodology. London: Sage, pp. 327-343.

Winter, S., Maslowska, E., Vos, A.L., 2021. The effects of trait-based personalization in social media advertising. Computers in Human Behavior 114, art. no. 106525.

Yang, S., Lin, S., Carlson, J.R., Ross, W.T. Jr., 2016. Brand engagement on social media: Will firms' social media efforts influence search engine advertising effectiveness? Journal of Marketing Management 32 (5-6), 526-557.

Youn, S., Kim, S., 2019. Understanding ad avoidance on Facebook: Antecedents and outcomes of psychological reactance. Computers in Human Behavior 98, 232-244.

Zimmer, F., Scheibe, K., Stock, W.G., 2018, A model for information behavior research on social live streaming services (SLSSs), in G. Meiselwitz, ed., Social Computing and Social Media. Technologies and Analytics. $10^{\text {th }}$ International Conference, SCSM 2018, Held as Part of HCI International 2018, Las Vegas, NV, USA, July 15-20, 2018, Proceedings, Part II. Cham, Switzerland: Springer (Lecture Notes in Computer Science; 10914), pp. 429-448.

Zuckerberg, M., 2018. One of our big focus areas for 2018 is making sure the time we all spend on Facebook is time well spent [Facebook status update]. Retrieved Aug 25, 2020, from https://www.facebook.com/zuck/posts/10104413015393571 